Journal of

Nutrigenetics

Nutrigenomics
J Nutrigenet Nutrigenomics 2008;1:155-171

DOI: $\underline{10.1159 / 000113657}$
Received: July 23, 2007

Accepted: October 5, 2007

Published online: January 17, 2008

\title{
Transcriptional Profiling of Chromosome 17 Quantitative Trait Loci for Carbohydrate and Total Calorie Intake in a Mouse Congenic Strain Reveals Candidate Genes and Pathways
}

\author{
K. Ganesh Kumar Brenda K. Smith Richards \\ Division of Experimental Obesity, Pennington Biomedical Research Center, Louisiana State University System, \\ Baton Rouge, La., USA
}

\section{Key Words \\ QTL mapping • Mouse chromosome $17 \cdot$ Congenic • Microarray · Food intake}

\begin{abstract}
Background/Aims: The genetic basis for ingestive behaviors is virtually unknown. Quantitative trait loci (QTLs) for carbohydrate and energy intake map to mouse chromosome 17 and were previously confirmed by a congenic strain bearing CAST/Ei (CAST) donor segment on the C57BL/6J (B6) background. Methods: We used microarray technology to facilitate gene identification. Gene expression was compared between the B6.CAST-17 (BC-17) congenic and B6 strains in two diets: (1) chow, and (2) carbohydrate/protein vs. fat/protein. Results: Within the QTL and unique to macronutrient selection, Agpat1 (acylglycerol-3-phosphate O-acyltransferase 1) was differentially expressed in hypothalamus. Irrespective of diet, the gene with the highest fold difference in congenic mice was trefoil factor 3 (Tff3) in liver. Several genes involved in fat metabolism were decreased in carbohydratepreferring congenic mice, while genes associated with carbohydrate metabolism were increased. In particular, the glyoxalase pathway was enhanced including Glo1, Glo2, and $d L D H$. Higher expression of Glo1 mRNA in BC-17 congenic mice corresponded to increased protein expression revealed
\end{abstract}

\begin{tabular}{ll}
\hline KARGER & ๑ 2008 S. Karger AG, Basel \\
Fax +41613061234 & \\
$\begin{array}{l}\text { E-Mail karger@karger.ch } \\
\text { www.karger.com }\end{array}$ & $\begin{array}{l}\text { Accessible online at: } \\
\text { www.karger.com/jnn }\end{array}$
\end{tabular}

by Western blot, and to higher GLO1 activity in blood. Conclusion: These genes represent new candidates for nutrient intake phenotypes. We propose that increased GLO1 in the BC-17 strain supports its need to protect against dietary oxidants resulting from high carbohydrate intake.

Copyright $\odot 2008$ S. Karger AG, Basel

\section{Introduction}

Both humans [1-7] and laboratory animal strains display highly variable intakes of high-fat and high-carbohydrate foods. In rodent models, a genetic basis for the observed variation in self-selected macronutrient intake was proposed as early as the 1940s $[8,9]$ based on the observation of 'similar appetites' among littermate rats. These observations were underscored by later evidence that intra-litter variation in fat and carbohydrate selection is smaller than inter-litter variation [10], as well as reports of within- and between-strain differences in rodents [11-15], which suggest a combination of genetic and environmental factors. In an evaluation of thirteen mouse inbred strains, we found continuous variation in macronutrient consumption across strains, thus providing clear evidence for a complex genetic trait [16]. These results allowed for the identification of a suitable animal model,
Brenda K. Smith Richards, PhD

Pennington Biomedical Research Center

6400 Perkins Road

Baton Rouge, LA 70808-4124 (USA)

Tel. +1 225763 2562, Fax +1 225763 2525, E-Mail richarbk@pbrc.edu 
i.e. two strains displaying non-overlapping phenotypic distributions were chosen for genetic analysis: C57BL/6J (B6) mice self-select a higher proportion of energy from fat than CAST/Ei (CAST), a strain that consumes more carbohydrate [16]. The CAST strain was also noted for its significantly higher calorie intake per body weight.

To begin identifying the complex trait genes underlying these phenotypic differences, we first established statistically significant, genome-wide linkage or association. Using a large $F_{2}$ intercross population, the first mammalian QTL for macronutrient-specific intake (carbohydrate and fat) and for total energy intake were identified [17]. A region on proximal Chr 17 revealed two significant QTL that co-localized for increased macronutrient intake-carbohydrate (Mnic1) and total kilocalorie intake (Kcal2), adjusted for body weight. Next, we developed a congenic strain to obtain independent evidence for linkage, to determine the locus more precisely, and to aid in identification of the underlying gene(s). The congenic line was constructed by introgressing CAST donor DNA from the Mnicl and Kcal 2 QTL on Chr 17 in a genome identical to the background B6 strain [18]. This B6.CAST-17 congenic strain confirmed the chromosome 17 locus by specifying the original linked traits; specifically, homozygous congenic mice consumed significantly more carbohydrate (27\%) and total energy (17\%) compared with wild-type B6 littermates [18]. This complex QTL region has been localized to a 34.8-cM region, which corresponds to $60.3 \mathrm{Mb}$ on mouse chromosome 17.

With the QTL captured in an interval-specific congenic strain that exhibits the original linked phenotypes, the molecular basis of the effects of this genetic locus on nutrient intake can be elucidated. Comprehensive microarray analyses of genes in the hypothalamus and liver were performed to reveal changes in expression between the wild-type B6 and B6.CAST-17 congenic mice [18]. Transcriptional differences outside the target QTL were examined to identify regulatory pathways or downstream targets relevant to the control of food intake. To identify genes that were uniquely associated with macronutrient selection, and not with chow intake, two independent experiments were conducted with respect to diet, i.e. chow and 2-choice macronutrient diet. The results permit qualitative comparisons of the two sets of differentially expressed genes. The differential expression of genes was validated with quantitative RT-PCR using the same RNA samples that were subjected to microarrays. The results of this study provide the basis for further investigation of differentially expressed candidate genes within Mnicl and Kcal2, with a potential role in preferential carbohy- drate consumption and increased calorie intake. This is the first microarray study aimed at identifying candidate genes involved in the control of ingestive behaviors related to the selection of macronutrients.

\section{Methods}

\section{Animals}

C57BL/6J (B6) and CAST/Ei (CAST) breeders were purchased from the Jackson laboratory (Bar Harbor, Me., USA). A full congenic strain, B6.CAST ${ }^{\text {D17Mit19-D17Mit91 }}$ (B6.CAST-17) was developed on site at the Pennington Biomedical Research Center using the 'speed congenics' method as previously described [18, 19]. Selection at each generation was based on the presence of desired genomic segment and the absence of contaminating donor DNA [19].

The marker-assisted selection protocol produces congenic strains in less than half the number of generations required by the classic protocol $\left(\mathrm{N}_{12}\right)$ and by S6, a 'speed congenic' line has $<0.25 \%$ contaminating donor genome [19]. The B6.CAST-17 S6 ('speed' congenic generation 6) strain possesses a 34.8-cM CAST donor segment on the B6 background, extending at least from proximal marker D17Mit19 at 4.7 Mb to distal marker D17Mit91 at $65.2 \mathrm{Mb}$, containing $60.5 \mathrm{Mb}$. To generate experimental animals, heterozygous B6.CAST-17 mice were intercrossed to generate three (littermate) genotypes.

All mice used as controls for the congenic animals were littermate B6. The use of littermate controls to test the phenotypic effect of a congenic segment is extremely important for overcoming the problems of background heterogeneity as well as the effects of litter, age, or other unidentified environmental factors.

Mice were bred and reared in polycarbonate cages with sterilized corn-cob bedding, and housed in temperature-controlled rooms at $23-24^{\circ} \mathrm{C}$ with a $14: 10$-hour light-dark cycle. Mice were weaned onto standard rodent chow (no. 5001, LabDiet, Richmond, Ind., USA) which contained by energy $28 \%$ protein, $12 \%$ fat, and $60 \%$ carbohydrate. Animal studies were carried out with the approval of the PBRC Institutional Animal Care and Use Committee.

\section{Phenotyping}

Phenotyping methods have been previously described in detail, including diet composition [17]. Briefly, 8-week-old mice were adapted to single housing in hanging, wire-bottomed mouse cages at $25-27^{\circ} \mathrm{C}$ until they regained positive weight balance. The light/dark cycle was set at 12:12 h. Mice were presented with a choice between two diets: fat/protein (F/P; vegetable shortening and casein) and carbohydrate/protein $(\mathrm{C} / \mathrm{P}$; corn starch, powdered sugar, and casein). The protein composition of the two diets was equivalent (22\% of energy) and the balance of calories for each was contributed by fat or carbohydrate (78\%). Both diets were supplemented with vitamins, minerals, and cellulose. Diet jars and all spillage were weighed daily.

For the low- and high-carbohydrate study, mice of each strain were fed a single nutritionally complete diet: D12331 or D12329, respectively (Research Diets, Inc., New Brunswick, N.J., USA) for 2 days. On the day of tissue harvest, mice were food-deprived at $08.00 \mathrm{~h}$ and euthanized at $14.00 \mathrm{~h}$. 


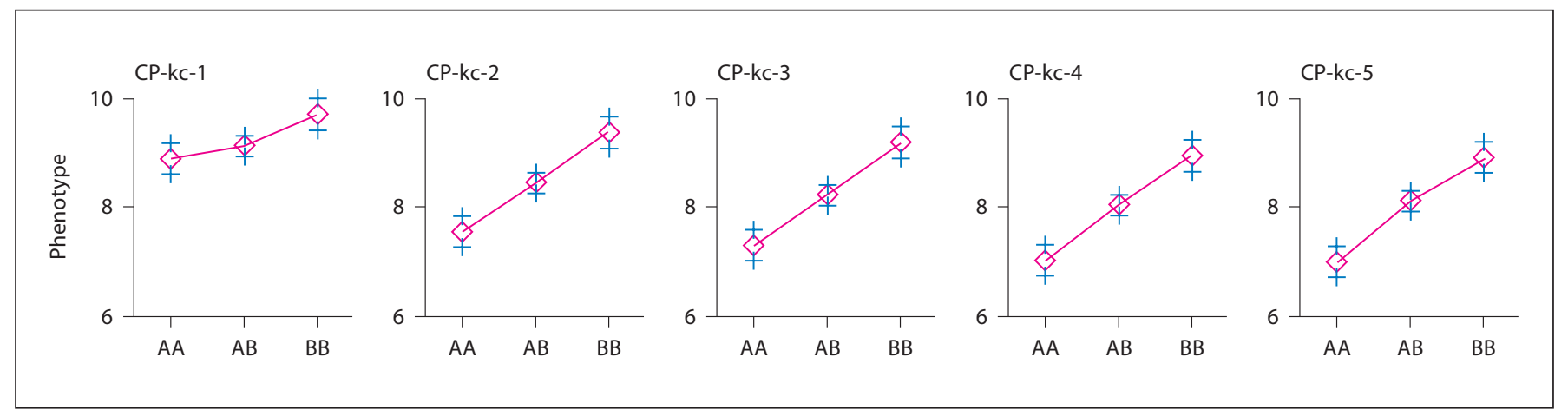

Fig. 1. Direction of QTL effects on Chr17. Genetic linkage for carbohydrate/protein $\mathrm{kcal}(\mathrm{C} / \mathrm{P} \mathrm{kc})$ intake on days $1-5$ in $\mathrm{F}_{2}$ mice derived from an intercross of C57BL/6J and CAST/EiJ (42). $\mathrm{F}_{2}$ mice showed an absence of genetic linkage on day 1 , but not on days 2 and following, for $\mathrm{C} / \mathrm{P} \mathrm{kcal}$ at the Mnic1 QTL locus (D17Mit100), and the temporal variation in linkage was due to the $\mathrm{B} 6$ allele. $\mathrm{AA}=$ Homozygous $\mathrm{B} 6$ allele; $\mathrm{AB}=$ heterozygous for $\mathrm{B} 6$ and CAST alleles; $\mathrm{BB}=$ homozygous CAST allele.
Fig. 2. a Macronutrient diet selection data for carbohydrate/protein $(\mathrm{C} / \mathrm{P})$ and fat/ protein $(\mathrm{F} / \mathrm{P})$ intake on days 1 and 2 of diet initiation in the 10-day phenotyping study. Wild-type B6 mice, but not homozygous B6.CAST-17 (BC-17) congenic mice, significantly reduced their carbohydrate intake from day 1 to day $2 .{ }^{*} \mathrm{p}<0.001$. By contrast, there was no difference in $\mathrm{F} / \mathrm{P}$ intake between days 1 and 2 for either strain. b Total calorie (kcal) intake per $20 \mathrm{~g} \mathrm{BW}$ on days 1 and 2 of diet initiation. ${ }^{\dagger} \mathrm{p}<$ $0.002,{ }^{*} \mathrm{p}<5.7 \times 10^{-7}$.

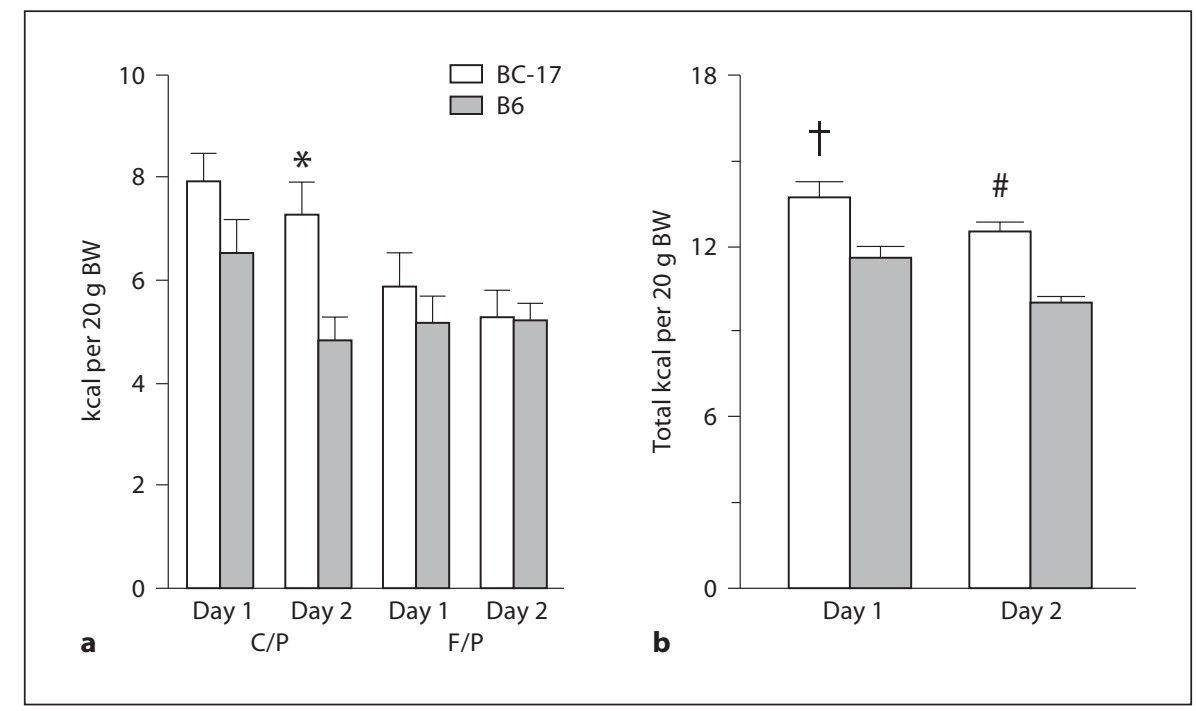

\section{Rationale for Experimental Design with Respect to Time \\ Course of Diet Exposure}

In the original QTL study, $\mathrm{F}_{2}$ mice showed an absence of genetic linkage on day 1 but not on days $2-10$, for $\mathrm{C} / \mathrm{P} \mathrm{kcal}$ at the Mnic1 QTL locus (D17Mit100). This temporal variation was attributed to the B6 allele [17] (fig. 1). This phenomenon also was observed in the congenic strain model used in the present study, i.e. there were no differences between day 1 and day 2 in $\mathrm{C} / \mathrm{P}$ intake of the homozygous B6.CAST-17 mice [18]. By contrast, the wild-type $\mathrm{B} 6$ and heterozygous congenic mice ate more $\mathrm{C} / \mathrm{P}$ calories on day 1 , but then significantly reduced their carbohydrate intake beginning on day 2. Notably, there were no temporal variations in F/P intake (fig. 2a). These results suggest that the choice of fat or carbohydrate may be affected by environmental factors during the first $24 \mathrm{~h}$ of exposure to the experimental diets but comes under a greater degree of genetic control with prolonged exposure. Based on the hypothesis that metabolic signals arising from ingestion of the diet on day 1 influenced the animals' choice on day 2 , tissues were collected shortly before onset of the dark feeding period on day 2 .

\section{Experimental Design}

Global gene expression, in both the hypothalamus and liver, was compared between the B6.CAST-17 homozygous congenic and B6 strains in two diet conditions: (exp.1) chow (LabDiet \#5001) and (exp. 2) carbohydrate/protein vs. fat/protein, $28 \mathrm{~h}$ after diet initiation, i.e. $4 \mathrm{~h}$ before lights out on day 2. For each experiment, RNA was pooled from 6 male B6.CAST-17 homozygous congenic mice and 6 male wild-type B6 mice. In experiment 2, animals were selected based on the absence of overlap in phenotypic values. To identify these individuals, mice of each strain $(\mathrm{n}=20-25)$ were tested in the diet selection protocol for 10 days [data presented in 18]. Six congenic and 6 B6 mice which displayed the most divergent phenotypic values for carbohydrate and total 
kcal intake (relative to body weight) were chosen for microarray analysis, returned to chow for 6 weeks, and then exposed to the 2 -choice diet for 1 day. With this design, we aimed to study gene expression changes immediately prior to selection of the $\mathrm{C} / \mathrm{P}$ or $\mathrm{F} / \mathrm{P}$ diet, and to avoid the confounding effects of novelty on day 1 , overnight fasting, or recent meals. On day 2 , food was removed at $13.00 \mathrm{~h}$ during the light period; $4 \mathrm{~h}$ later mice were quickly anesthetized by isoflurane inhalation and decapitated $\sim 1 \mathrm{~h}$ before lights out.

Ingestive behavior is a highly integrated process involving a number of metabolic systems [20]. Substantial evidence indicates that intracellular utilization of metabolic fuels generates signals that are used by the central nervous system (CNS) to control feeding [20] and several metabolic processes have been implicated, e.g. glucose utilization, fat oxidation, hepatic ATP content, and energy expenditure [22-26]. We reasoned that genes encoding proteins involved in these processes are likely candidates for modifying the self-selected intake of macronutrients. The hypothalamus and liver were selected for analysis based on their importance in the behavioral and metabolic control of food intake.

Genes with a 1.5 -fold change or greater were chosen for further consideration. Results for selected candidates were validated using qRT-PCR to compare gene expression in B6.CAST-17 homozygous congenic and wild-type B6 mice. Two independent experiments were conducted with respect to diet, i.e. chow and 2choice macronutrient diet. The two datasets permitted qualitative comparisons of the sets of differentially expressed genes between experiments.

\section{RNA Isolation and cDNA Synthesis}

Total RNA was isolated from liver and hypothalamus of B6. CAST-17 congenics and wild-type B6 mice using TRIzol (TRI reagent, Molecular Research Center). RNA was purified using the RNeasy kit (Qiagen). The quantity and quality of RNA was checked using Agilent bioanalyzer (Agilent Technologies). The samples with RIN $>8.0$ were selected for microarray analysis. First-strand cDNA templates were synthesized by mixing $1 \mu \mathrm{g}$ of RNA and $5 \mu \mathrm{M}$ of the $(\mathrm{dT})_{11}$ primer. The mixtures were heated for $5 \mathrm{~min}$ at $70^{\circ} \mathrm{C}$ and placed immediately on ice. Next, $1 \times$ RT buffer, 200 units Superscript II reverse transcriptase (Invitrogen), $25 \mu \mathrm{M}$ $\mathrm{dNTP}$, and $10 \mathrm{mM}$ DTT were added and incubated for $90 \mathrm{~min}$ at $42^{\circ} \mathrm{C}$ in a final volume of $20 \mu \mathrm{l}$. After heat inactivation of enzyme for $5 \mathrm{~min}$ at $70^{\circ} \mathrm{C}$, the $\mathrm{cDNA}$ was diluted to $1: 5$ with nuclease free water and stored at $-20^{\circ} \mathrm{C}$.

\section{Microarray Analysis}

The Applied Biosystems (AB) Mouse Genome Survey Microarray was used to generate gene expression profiles. This microarray consists of approximately 34,000 features including a set of $\sim 1,000$ controls. Each microarray contains 32,996 probes targeted to 32,381 curated genes representing 44,498 transcripts. There are more than 1,138 known genes in the Chr 17 QTL region (NCBI) and approx. $85 \%$ of these are represented in the $\mathrm{AB}$ mouse genome array. $1 \mu \mathrm{g}$ of total RNA was used to synthesize digoxigenin-UTP labeled cRNA using the AB chemiluminescent RT-IVT labeling Kit v2.0. Each microarray was first hybridized at $55^{\circ} \mathrm{C}$ for $1 \mathrm{~h}$ in hybridization buffer with blocking reagent. Next, $15 \mu \mathrm{g}$ of labeled cRNA targets was fragmented into 100-400 bases by incubating with fragmentation buffer at $60^{\circ} \mathrm{C}$ for $30 \mathrm{~min}$, mixed with internal control target and hybridized to each prehybridized microarray at $55^{\circ} \mathrm{C}$ for $16 \mathrm{~h}$. After hybridization, the arrays were washed and rinsed. Enhanced chemiluminescent signals were generated by first incubating arrays with anti-digoxigenin-alkaline phosphatase, enhanced with chemiluminescence-enhancing solution and finally in chemiluminescence substrate. Images were collected using a 1700 analyzer (Applied Biosystems, Foster City, Calif., USA) equipped with a high-resolution, large format CCD camera. Images were auto-girded and the chemiluminescent signals were quantified, corrected for background and spot, and spatially normalized. AB expression system software was used to extract assay signal and signal-to-noise ratio values from the microarray images. Bad spots $(<0.5 \%$ of genes) flagged by the software were removed. The assay signal was normalized across arrays using quantilequantile normalization with R-script from Applied Biosystems [27]. Signal-to-noise ratios of less than 3.0 and flagged genes with values greater than 5,000 were eliminated from the analysis. The normalized, log-transformed, background-corrected data were then analyzed using Spotfire DecisionSite Software v16.0 (Spotfire, Somerville, Mass., USA). Fold changes were calculated for each gene using the normalized signal values. Hybridization data and parameter information were deposited in the Gene Expression Omnibus (GEO) database (http://www.ncbi.nlm.nih.gov/geo/) under the GEO series accession number GSE6507.

\section{Bioinformatics Approach to Candidate Gene Identification}

The Protein ANalysis THrough Evolutionary Relationships (PANTHER) gene ontology and classification database (www. pantherdb.org) was used to identify perturbed signaling pathways and biological processes. This system classifies genes by their functions based on published reports, and uses evolutionary relationships to predict function in the absence of direct experimental evidence. Gene information and sequences were obtained from PANTHER and EMBL V31 (http://www.ensembl.org). A manual inspection of genes within the QTL region, to identify potential candidates not captured by PANTHER analysis, revealed that genes within the glyoxalase system were overexpressed in congenics. This observation led to an examination of genes upstream of the glyoxalase pathway and the discovery of several glycolytic genes with increased expression in congenic mice.

\section{Selection of Candidate Genes for Validation}

The chromosomal location of genes was determined using AB annotation. Because genetic variation underlying the nutrient intake traits resides within the QTL, a search of the literature was carried out for all differentially expressed genes in this region with possible physiological relevance, e.g. those pertaining to carbohydrate or lipid metabolism, the regulation of food intake, peripheral sensing pathways, or energy homeostasis. QTL region genes with the highest fold differences, as well as any receptors or receptor signaling genes, were also selected.

The CAST/Ei and C57BL/6J strains are highly polymorphic. Because commercial microarray probes are usually designed for B6 DNA sequence, they may not be suitable for CAST/Ei. To overcome this problem, we validated the gene expression results with qPCR using SYBR green, with primers that amplified a region different from the probe binding site. In this way, false-positives in the microarray results that could be due to a SNP(s) in the probe binding site were eliminated. 
Table 1. QTL region genes that were differentially expressed in hypothalamus

\begin{tabular}{|c|c|c|c|c|}
\hline Probe ID & Gene name & UniGene ID & Chow & $\begin{array}{l}\text { Macronutrient } \\
\text { selection diet }\end{array}$ \\
\hline 825725 & t-complex testis expressed 1 & Mm 948 & -3.58 & 2.60 \\
\hline 797869 & testis-specific gene A2 & Mm 2743 & -3.24 & 4.82 \\
\hline 667698 & unassigned & Mm.195061 & -2.87 & 1.76 \\
\hline 919579 & cytochrome P450 family 4 subfamily f polypeptide 15 & Mm.26539 & -2.7 & 2.0 \\
\hline 430779 & unassigned & Mm.33042 & -2.48 & 1.61 \\
\hline 595996 & ribosomal protein L7-like 1 & Mm.218533 & -2.13 & 1.73 \\
\hline 619090 & RAB26 member RAS oncogene family & Mm.266033 & -2.03 & 1.56 \\
\hline 353516 & RIKEN cDNA B230354K17 gene & Mm.206588 & -1.93 & 1.99 \\
\hline 905863 & $\mathrm{Rab} / \mathrm{GAB} \mathrm{TBC}$ related & Mm.301585 & -1.69 & 2.20 \\
\hline 505490 & zinc finger protein 40 & Mm.21025 & -1.56 & -3.95 \\
\hline 880965 & heat shock protein & Mm.372314 & -1.46 & 1.79 \\
\hline 846025 & unassigned & Mm.258491 & -1.38 & -1.74 \\
\hline 904144 & ribosomal protein $\mathrm{S} 2$ & Mm.362197 & -1.36 & 1.57 \\
\hline 529509 & zinc finger and BTB domain containing 12 & Mm 61119 & -1.3 & -1.76 \\
\hline 919204 & RIKEN cDNA 1200007D18 gene & Mm.30496 & -1.29 & -2.90 \\
\hline 896599 & ribosomal protein S2 & Mm.328846 & -1.29 & 1.52 \\
\hline 338441 & methylmalonyl-coenzyme A mutase & Mm.259884 & -1.23 & 1.61 \\
\hline 841838 & zinc finger protein 40 & Mm.21025 & -1.16 & -1.68 \\
\hline 558496 & unassigned & Mm.35016 & -1.16 & -1.85 \\
\hline 919791 & phosphodiesterase 10A & Mm.87161 & -1.03 & -1.50 \\
\hline 432416 & pre-B cell leukemia transcription factor 2 & Mm.7103 & 2.17 & 2.07 \\
\hline 742093 & RIKEN cDNA 2400010G15 gene & Mm 2787 & 2.27 & -1.62 \\
\hline 558559 & BTB (POZ) domain containing 9 & Mm.41220 & 2.38 & -1.51 \\
\hline 418927 & $\mathrm{~N}$-acetylglucosamine-1-phosphotransferase-gamma & Mm.38607 & 2.46 & -1.56 \\
\hline 869343 & radial spokehead-like 2 & Mm.359991 & 2.47 & -2.40 \\
\hline 465717 & mitochondrial carrier homolog 1 (C. elegans) & Mm.285322 & 2.66 & -2.27 \\
\hline 915442 & glyoxalase 1 & Mm.261984 & 2.71 & 1.59 \\
\hline 741537 & histocompatibility $2 \mathrm{~K} 1 \mathrm{~K}$ region & Mm 6771 & 3.07 & -2.09 \\
\hline 458119 & phospholipase C-like 2 & Mm.217362 & 3.26 & -1.59 \\
\hline 925126 & trinucleotide repeat containing 5 & Mm.240325 & 3.48 & -1.94 \\
\hline 768402 & cDNA sequence BC008155 & Mm.26783 & 3.5 & -1.87 \\
\hline 742757 & cullin 7 & Mm.329078 & 3.74 & -1.54 \\
\hline 706669 & RIKEN cDNA 1500032D16 gene & Mm.28349 & 4.11 & 2.80 \\
\hline 370857 & ectonucleotide pyrophosphatase/phosphodiesterase 5 & Mm.30145 & 7.43 & -2.47 \\
\hline 811338 & RAB5A member RAS oncogene family & Mm.329123 & 14.9 & -1.71 \\
\hline 761588 & TATA box-binding protein (TBP)-associated factor & Mm.267998 & 35.9 & -3.47 \\
\hline
\end{tabular}

\section{Quantitative Real-Time RT-PCR}

Expression candidates were validated by RT-PCR by means of an AB Prism 7900HT Sequence Detection System using SYBR green and gene-specific primers designed using Primer Express software (AB). Briefly, each $30 \mu \mathrm{l}$ reaction volume consisted of $1 \mu \mathrm{l}$ of cDNA from $100 \mu \mathrm{l}$ cDNA synthesized from $1 \mu \mathrm{g}$ of total RNA, 30 pmol of forward primer, and $30 \mathrm{pmol}$ of reverse primer in $2 \times$ SYBR green master mix (AB). Relative mRNA levels were determined in duplicate samples using a standard curve generated by a pool of RNA samples and normalized to values of the control gene Ppia. Ppia was chosen as the housekeeping gene because it does not show a constitutive difference in the strains and tissues of interest.

Transcriptional Analyses of Nutrient Intake QTL

\section{Western Blots}

Protein was extracted from the liver of B6.CAST-17 and WT mice. Approx. $500 \mathrm{mg}$ of tissue was powdered in liquid nitrogen, homogenized and sonicated in $500 \mu$ l RIPA buffer containing 100 $\mathrm{mM}$ Tris- $\mathrm{HCl}$ ( $\mathrm{pH} 8.0$ ), 0.1\% SDS, $150 \mathrm{~mm} \mathrm{NaCl,} 50 \mathrm{~mm}$ EDTA, $0.1 \%$ NP40, $0.1 \%$ sodium deoxycholate, $100 \mathrm{~mm}$ beta-glycerophosphate and $50 \mu \mathrm{l}$ of protease inhibitor cocktail (Sigma). $\sim 200$ $\mu \mathrm{g}$ of protein was separated in 12\% SDS-PAGE and transferred onto a polyvinylidene difluoride membrane (Millipore) for immunoblotting. The membrane was blocked in Odyssey buffer (LICOR Bioscience, Lincoln, Nebr., USA). The membrane was immunoblotted with antibody to Glol (kindly provided by Dr. Kenneth Tew) or mouse $\beta$-actin (Abcam, Cambridge, Mass., USA) overnight at $4{ }^{\circ} \mathrm{C}$, followed by fluorescent-labeled secondary antibody (IRDye $800^{\mathrm{TM}}$ or Cy5.5) for $1 \mathrm{~h}$. Signal intensity was normal- 
Table 2. QTL region genes that were differentially expressed only in chow or macronutrient selection diet in hypothalamus

\begin{tabular}{|c|c|c|c|}
\hline Probe ID & Gene name & UniGene ID & Fold change \\
\hline \multicolumn{4}{|l|}{ Chow } \\
\hline 548781 & RIKEN cDNA 1700110C19 & & -2.23 \\
\hline 790322 & unassigned & & -1.57 \\
\hline 485013 & Nurim (nuclear envelope membrane protein) & Mm.279713 & 2.48 \\
\hline \multicolumn{4}{|c|}{ Macronutrient selection diet } \\
\hline 853033 & unassigned & & -13.80 \\
\hline 871613 & cytochrome P450, family 4, subfamily f, polypeptide 14 & Mm.426027 & -12.23 \\
\hline 628220 & histocompatibility 2 , $\mathrm{T}$ region locus 24 & Mm.14573 & -8.83 \\
\hline 795040 & $\mathrm{CD} 2$ associated protein & $\mathrm{Mm} .218637$ & -3.53 \\
\hline 906572 & $\begin{array}{l}\text { nuclear factor of kappa light polypeptide gene enhancer in } \\
\text { B cells inhibitor, epsilon }\end{array}$ & Mm.57043 & -2.65 \\
\hline 350018 & ubiquitin protein ligase E3 component n-recognin 2 & Mm.28234 & -2.56 \\
\hline 731526 & RIKEN cDNA D130084M03 gene & Mm.130244 & -2.45 \\
\hline 638437 & hypothetical protein LOC638437 & & -2.31 \\
\hline 300048 & phospholipase A2, group VII & Mm.9277 & -2.27 \\
\hline 561631 & expressed sequence AI662250 & Mm.37290 & -260 \\
\hline 932548 & $\begin{array}{l}\text { 1-acylglycerol-3-phosphate O-acyltransferase } 1 \\
\text { (lysophosphatidic acid acyltransferase, alpha) }\end{array}$ & Mm.8684 & -2.10 \\
\hline 333538 & RIKEN cDNA $9030612 \mathrm{M} 13$ gene & Mm.38813 & -1.97 \\
\hline 421019 & Carbonic anhydrase 15 & Mm.379878 & -1.94 \\
\hline 647051 & Unassigned & & -1.90 \\
\hline 764311 & DNA segment, Chr 17, Wayne State University 104, expressed & Mm.294870 & -1.88 \\
\hline 928306 & Transporter 2, ATP-binding cassette, sub-family B (MDR/TAP) & Mm.14814 & -1.86 \\
\hline 734426 & CASK interacting protein 1 & Mm.70989 & -1.85 \\
\hline 885645 & Cytochrome p450, subfamily $4 \mathrm{~F}$ & & -1.77 \\
\hline 571554 & Tumor necrosis factor (ligand) superfamily, member 9 & Mm.41171 & -1.76 \\
\hline 834440 & cDNA sequence BC052046 & Mm.234640 & -1.74 \\
\hline 581260 & mannose-6-phosphate receptor binding protein 1 & Mm.311696 & -1.73 \\
\hline 772704 & RIKEN cDNA 4932442K08 gene & Mm.35039 & -1.72 \\
\hline 580017 & RIKEN cDNA 0610007P22 gene & Mm.180687 & -1.72 \\
\hline 898923 & Gem (nuclear organelle) associated protein 6 & Mm.279985 & -1.68 \\
\hline 439922 & regulator of G-protein signaling 11 & Mm.109840 & -1.65 \\
\hline 618358 & tripartite motif protein 39 & Mm.40624 & -1.64 \\
\hline 766610 & $\mathrm{H} 2-\mathrm{K}$ region expressed gene 2 & Mm.2948 & -1.61 \\
\hline 835651 & tumor necrosis factor receptor superfamily, member 21 & Mm.200792 & -1.61 \\
\hline 424542 & alanyl-tRNA synthetase like & Mm.329063 & -1.58 \\
\hline 639092 & RIKEN cDNA 9030612M13 gene & Mm.38813 & -1.54 \\
\hline 454588 & AT rich interactive domain $1 \mathrm{~B}$ & Mm.133401 & -1.53 \\
\hline 672192 & hypothetical gene supported by AK086736 & Mm.237134 & -1.52 \\
\hline 766979 & gene model $942(\mathrm{NCBI})$ & Mm.329216 & -1.52 \\
\hline 673839 & ATP-binding cassette, sub-family A, member 3 & Mm.250280 & -1.51 \\
\hline 326220 & mitochondrial ribosomal protein $\mathrm{S} 10$ & Mm.216250 & -1.51 \\
\hline 795197 & transducin (beta)-like 3 & Mm.100353 & -1.51 \\
\hline 748793 & WD repeat domain 27 & Mm.379200 & 1.50 \\
\hline 842988 & General transcription factor II H, polypeptide 4 & Mm.10182 & 1.51 \\
\hline 915872 & thrombospondin 2 & Mm.26688 & 1.52 \\
\hline 850068 & fibronectin type III domain containing 1 & Mm.379161 & 1.55 \\
\hline 887858 & protein phosphatase 1 , regulatory subunit 10 & Mm.29385 & 1.55 \\
\hline 414701 & nuclear prelamin A recognition factor-like & Mm.24201 & 1.55 \\
\hline 346435 & lymphocyte antigen 6 complex, locus G5C & Mm.222643 & 1.56 \\
\hline 490554 & zinc finger protein 422 , related sequence 1 & Mm.276296 & 1.56 \\
\hline 344295 & SRY-box containing gene 8 & Mm.258220 & 1.57 \\
\hline 656267 & RIKEN cDNA C230029D21 gene & Mm.373631 & 1.59 \\
\hline
\end{tabular}


Table 2 (continued)

\begin{tabular}{llll}
\hline Probe ID & Gene name & UniGene ID & Fold change \\
\hline 732848 & histocompatibility 2, blastocyst & Mm.34289 & 1.60 \\
801941 & Wilms' tumor 1-associating protein & Mm.275521 & 1.72 \\
750011 & cytochrome P450, family 4, subfamily f, polypeptide 13 & $\mathrm{Mm} .254838$ & 1.75 \\
478237 & RIKEN cDNA A730055L17 gene & $\mathrm{Mm} .358998$ & 1.81 \\
586542 & Zinc finger protein 161 & $\mathrm{Mm} .29434$ & 1.81 \\
704678 & Lipin 2 & $\mathrm{Mm} .227924$ & 1.88 \\
773606 & Riken cDNA C530047H08 gene & $\mathrm{Mm} .124373$ & 1.97 \\
577870 & Mannosidase 2, alpha 1 & $\mathrm{Mm} .2433$ & 2.37 \\
298384 & Unassigned & $\mathrm{Mm} .268383$ & 2.60 \\
371577 & Transcription factor 19 & $\mathrm{Mm} .11434$ & 3.03 \\
602187 & t-complex-associated testis expressed 1 & $\mathrm{Mm} .1290$ & 3.32 \\
\hline
\end{tabular}

ized with $\beta$-actin and quantified using the Odyssey imaging system (LI-COR Bioscience).

\section{Determination of Glyoxalase 1 Activity}

Glyoxalase 1 activity was measured according to the method of Han et al. [28]. An assay mixture containing $1 \mathrm{ml}$ of glyoxalase buffer at pH $7.0\left(0.028 \mathrm{M} \mathrm{NaHPO}_{4}, 0.016 \mathrm{M} \mathrm{KH}_{2} \mathrm{PO}_{4}, 0.1 \mathrm{M} \mathrm{KCl}\right.$, $0.01 \mathrm{M} \mathrm{MgCl}_{2} \cdot 6 \mathrm{H}_{2} \mathrm{O}$ ), $20 \mu \mathrm{l}$ of $0.316 \mathrm{M}$ purified methylglyoxal (graciously provided by Dr. Dave Van der Jagt), and $20 \mu \mathrm{l}$ of $0.1 \mathrm{M} \mathrm{GSH}$ (Sigma) was incubated for $2 \mathrm{~min}$ at room temperature to form hemithioacetal. Initial $\mathrm{OD}_{240}$ was measured. Next, $2 \mu \mathrm{l}$ of blood sample was added and the enzymatic production of $S$-lactoylglutathione $\left(\varepsilon 3.37 \mathrm{~mm}^{-1} \mathrm{~cm}^{-1}\right)$ was measured at $240 \mathrm{~nm}$ at $15-$ second intervals for $3 \mathrm{~min}$. Specific activity was expressed as $\mu \mathrm{mol}$ S-lactoylglutathione formed $/ \mathrm{min} / \mathrm{mg}$ protein.

\section{Statistical Analyses}

The effect of strain or diet on gene expression was determined by ANOVA. To allow for different variances for the two strains, the Satterthwaite approximation for degrees of freedom was applied. Individual comparisons were evaluated using Student's t test.

\section{Results}

Macronutrient Diet Selection Phenotypes

Consistent with our original linkage data (fig. 1) [17], the B6.CAST-17 congenic strain $(\mathrm{n}=20)$ consumed significantly more C/P kcal (34\%) and total kcal (20\%) per body weight on day 2, but not on day 1 of the 10 -day phenotyping period, when compared with wild-type B6 $(\mathrm{n}=$ 25) (fig. 1). By contrast, there was no strain difference in $\mathrm{F} / \mathrm{P}$ intake. All mice were then placed back on chow for 6 weeks. Next, a subset of mice with high and low phenotypic values were returned to the 2-choice diet for 1 day while the remaining animals were kept on chow (exp. 1).

Transcriptional Analyses of Nutrient Intake QTL
The mice selected for microarray analysis in experiment 2 (C/P vs. F/P diet) exhibited similar intakes in both the 10 - and 2-day phenotyping periods (Pearson $\mathrm{r}=0.71, \mathrm{p}<$ 0.01 , d.f. $=12-2)$.

\section{Expression of QTL Transcripts on Chow}

Microarray analysis revealed expression differences in the hypothalamus and liver between $\mathrm{BC}-17$ congenic and littermate wild-type $\mathrm{B} 6$ mice. The effects of diet on gene expression in these strains were studied by making qualitative comparisons of the two datasets obtained from separate sets of animals. In hypothalamus, 31 of $375 \mathrm{ex}-$ pressed genes were differentially expressed within the QTL segment. Of these, 18 genes were upregulated and 13 were downregulated in congenic mice compared with WT (tables 1, 2). In liver, 54 of 346 expressed genes were differential between the two strains, of which 32 were downregulated and 22 were upregulated in congenic mice (tables 3,4).

\section{Expression of QTL Transcripts on Macronutrient Selection Diet}

In hypothalamus, out of 426 expressed genes within the QTL interval, 38 were upregulated and 56 were downregulated in congenic mice compared with WT. In liver, out of 364 expressed genes in congenic mice, 52 were downregulated and 39 were upregulated.

\section{Expression of QTL Transcripts on Both Chow and Macronutrient Selection Diet}

In the hypothalamus, only one metabolic gene, Glo1 (glyoxalase 1), was differentially expressed between strains in both diet experiments. In liver, all the meta- 
Table 3. QTL region genes that were differentially expressed in liver (positive value in fold difference indicates an increase, and negative value indicates a decrease in congenic mice

\begin{tabular}{|c|c|c|c|c|}
\hline Probe ID & Gene name & UniGene ID & Chow & $\begin{array}{l}\text { Macronutrient } \\
\text { selection diet }\end{array}$ \\
\hline 716213 & 2-4-dienoyl-coenzyme A reductase 2, peroxisomal & Mm.292869 & -6.29 & -4.93 \\
\hline 761588 & $\begin{array}{l}\text { TAF11 RNA polymerase II TATA box binding protein } \\
\text { (TBP)-associated factor }\end{array}$ & Mm.267998 & -4.20 & -3.08 \\
\hline 871613 & cytochrome P450 family 4 subfamily f polypeptide 14 & Mm. 426027 & -3.42 & -2.95 \\
\hline 925126 & trinucleotide repeat containing 5 & Mm.240325 & -3.25 & -1.98 \\
\hline 804439 & apolipoprotein $\mathrm{M}$ & Mm.2161 & -3.09 & -2.92 \\
\hline 460449 & anaplastic lymphoma kinase & Mm.2536 & -2.66 & -1.59 \\
\hline 885645 & cytochrome $\mathrm{P} 450$ subfamily $4 \mathrm{~F}$ & & -2.51 & -2.00 \\
\hline 701966 & lymphocyte antigen 6 complex locus G6C & Mm.215096 & -2.34 & -2.12 \\
\hline 660078 & unassigned & & -2.25 & -2.09 \\
\hline 928591 & histocompatibility 2 Q region locus $10 ; \mathrm{H} 2-\mathrm{Q} 10$ & Mm.88795 & -2.21 & -2.26 \\
\hline 467910 & butyrophilin-like 1 & Mm.46284 & -2.18 & -1.84 \\
\hline 333538 & RIKEN cDNA 9030612M13 gene & Mm.38813 & -2.12 & -3.82 \\
\hline 707182 & polycystic kidney disease 1 homolog & Mm.290442 & -2.07 & -1.65 \\
\hline 356012 & $\begin{array}{l}\text { myeloid/lymphoid or mixed lineage-leukemia translocation to } \\
1 \text { homolog (Drosophila) }\end{array}$ & Mm.148748 & -1.97 & -1.56 \\
\hline 747504 & $\begin{array}{l}\text { sema domain, transmembrane domain, and cytoplasmic domain } \\
\text { (semaphorin) 6B }\end{array}$ & Mm.8029 & -1.92 & -1.71 \\
\hline 749204 & acetyl-CoA C-acyltransferase 2 & Mm.229342 & -1.91 & -2.02 \\
\hline 634113 & vitrin & Mm.292983 & -1.91 & -1.54 \\
\hline 477069 & fibroblast growth factor receptor substrate 3 & Mm.89912 & -1.87 & -1.60 \\
\hline 561631 & expressed sequence AI662250 & Mm.37290 & -1.82 & -1.72 \\
\hline 640886 & transmembrane protein 8 & Mm.304656 & -1.75 & 1.75 \\
\hline 581260 & mannose-6-phosphate receptor binding protein 1 & Mm.311696 & -1.75 & -2.45 \\
\hline 914762 & G protein-coupled receptor 108 & Mm.28468 & -1.68 & -1.66 \\
\hline 706669 & RIKEN cDNA 1500032 D16 gene & Mm.28349 & -1.63 & -2.19 \\
\hline 741537 & histocompatibility $2 \mathrm{~K} 1 \mathrm{~K}$ region & Mm.16771 & -1.61 & -1.79 \\
\hline 619946 & FK506 binding protein-like & Mm.10025 & -1.59 & -1.87 \\
\hline 742757 & cullin 7 & Mm.329078 & -1.58 & -2.09 \\
\hline 632987 & RIKEN cDNA 4930539E08 gene & Mm.248931 & -1.57 & -1.85 \\
\hline 932548 & $\begin{array}{l}\text { 1-acylglycerol-3-phosphate O-acyltransferase } 1 \\
\text { (lysophosphatidic acid acyltransferase alpha) }\end{array}$ & Mm.8684 & -1.52 & -1.75 \\
\hline 592477 & fibrillarin & Mm.379878 & -1.51 & -1.79 \\
\hline 433605 & LEM domain containing 2 & Mm.29689 & -1.45 & -1.69 \\
\hline 637912 & histocompatibility 2 class II antigen A beta 1 & Mm.254067 & -1.44 & -2.22 \\
\hline 807637 & histocompatibility $2 \mathrm{M}$ region locus 3 & Mm.14437 & -1.44 & -1.65 \\
\hline 350018 & ubiquitin protein ligase E3 component n-recognin 2 & Mm.28234 & -1.42 & -2.23 \\
\hline 801941 & Wilms' tumor 1-associating protein & Mm.275521 & -1.38 & -1.66 \\
\hline 309261 & RAB11B member RAS oncogene family & Mm.35727 & -1.36 & -2.00 \\
\hline 669667 & unassigned & Mm.276405 & -1.33 & -1.65 \\
\hline 425013 & RIKEN cDNA 1110018J12 gene & Mm.271817 & -1.31 & -1.65 \\
\hline 493546 & F-box and leucine-rich repeat protein 17 & Mm.379894 & -1.22 & 1.81 \\
\hline 764339 & RD RNA-binding protein & Mm.279907 & -1.20 & -1.69 \\
\hline 904214 & peptidyl-prolyl cis-trans isomerase A & & -1.16 & -1.62 \\
\hline 479998 & EH-domain containing 3 & Mm.18526 & -1.13 & -1.56 \\
\hline 864277 & mitochondrial ribosomal protein L18 & Mm.290166 & -1.07 & -1.51 \\
\hline 776724 & RIKEN cDNA 1700022C21 gene & Mm.26684 & -1.05 & -1.63 \\
\hline 924756 & TEA domain family member 3 & Mm.6655 & -1.03 & 3.58 \\
\hline 582898 & unassigned & & 1.03 & -1.80 \\
\hline 824604 & ankyrin repeat and SAM domain containing 1 & Mm.32556 & 1.04 & 2.06 \\
\hline 827226 & insulin-like growth factor 2 receptor & Mm.213226 & 1.12 & 1.60 \\
\hline 424542 & alanyl-tRNA synthetase like & Mm.329063 & 1.13 & 1.99 \\
\hline
\end{tabular}


Table 3 (continued)

\begin{tabular}{|c|c|c|c|c|}
\hline Probe ID & Gene name & UniGene ID & Chow & $\begin{array}{l}\text { Macronutrient } \\
\text { selection diet }\end{array}$ \\
\hline 672227 & ATP-binding cassette sub-family $\mathrm{G}$ member 5 & Mm.289590 & 1.20 & 1.86 \\
\hline 816939 & molybdenum cofactor synthesis 1 & Mm.22256 & 1.21 & -2.32 \\
\hline 725803 & multiple coagulation factor deficiency 2 & Mm.30251 & 1.24 & 1.65 \\
\hline 710361 & high mobility group AT-hook 1 & Mm.4438 & 1.25 & 2.82 \\
\hline 311119 & cell division cycle 5-like (S. pombe) & Mm.28270 & 1.26 & 1.74 \\
\hline 750011 & Cytochrome P450 family 4 subfamily f polypeptide 13 & Mm.254838 & 1.26 & 1.61 \\
\hline 730857 & Serine/arginine repetitive matrix 2 & Mm.5222 & 1.30 & -1.53 \\
\hline 915442 & Glyoxalase 1 & Mm.261984 & 1.32 & 1.66 \\
\hline 631849 & Protein phosphatase 1 regulatory (inhibitor) subunit 11 & Mm.46176 & 1.50 & 1.63 \\
\hline 735476 & HLA-B-associated transcript $1 \mathrm{~A}$ & Mm.126043 & 1.51 & 1.64 \\
\hline 585136 & KH-type splicing regulatory protein & & 1.67 & 1.64 \\
\hline 926995 & Zinc finger protein 598 & Mm.219581 & 1.67 & 1.68 \\
\hline 323513 & UDP-Gal:betaGalNAc beta 13 -galactosyltransferase polypeptide 4 & Mm.11132 & 1.69 & 2.14 \\
\hline 795197 & Transducin (beta)-like 3 & Mm.100353 & 1.73 & 1.87 \\
\hline 353516 & RIKEN cDNA B230354K17 gene & Mm.206588 & 1.76 & 1.72 \\
\hline 448315 & Expressed sequence AW049765 & Mm.204991 & 1.77 & 1.57 \\
\hline 846025 & Differentially expressed in FDCP 6 & Mm.267359 & 1.80 & 1.65 \\
\hline 621252 & Vascular endothelial growth factor A & $\mathrm{Mm} .282184$ & 1.92 & 1.55 \\
\hline 905863 & $\mathrm{RAB} / \mathrm{GAB}$ related & Mm.301585 & 1.94 & 2.71 \\
\hline 424409 & Cystathionine beta-synthase & Mm.206417 & 2.04 & 1.76 \\
\hline 661148 & Mesothelin & Mm.17510 & 2.16 & 1.75 \\
\hline 457113 & RIKEN cDNA 4930528F23 gene & Mm.52592 & 2.38 & 2.17 \\
\hline 441362 & Sulfotransferase family cytosolic $1 \mathrm{C}$ member 2 & Mm.19320 & 4.71 & 2.67 \\
\hline 856010 & Trefoil factor 3 & Mm.4641 & 79.74 & 9.61 \\
\hline
\end{tabular}

$\mathrm{Mm}=$ Mus musculus.

bolic genes that were altered in chow-fed animals were also regulated in mice on a macronutrient selection diet. A number of genes involved in fat metabolism were downregulated in carbohydrate-preferring, congenic mice including: ApoM (apolipoprotein M), Acat2 (acetylCoA C-acyltransferase 2), Agpat1 (acylglycerol-3-phosphate O-acyltransferase 1), and Decr2 (2-4-dienoyl-coenzyme A reductase 2, peroxisomal). By contrast, several genes associated with carbohydrate metabolism were upregulated in the congenic strain including: Glol (glyoxalase 1), Glo2 (glyoxalase 2), Igf2r (insulin-like growth factor 2 receptor), and $M 6 p b p 4$ (mannose-6-phosphate receptor binding protein 1) (downregulated). Other differentially expressed metabolic genes were: B3galt4 (UDPbeta-1,3-galactosyltransferase, polypeptide4) (increased), and Cyp4f14 (cytochrome p450, family 4; subfamily f) (decreased). Expression differences were also found for several transcription factors, i.e. Taf11 (TAF11 RNA polymerase II, TATA box binding protein (TBP)-associated factor), Rnaset2 (ribonuclease T2), Rps6Ka2 (ribosomal protein S6 kinase, polypeptide 2), and Tead3 (transcription enhancer factor domain family member 3 ).

\section{Glyoxalase Pathway and Glo1 Expression Analyses}

Transcriptional profiling revealed an upregulation of genes in the glyoxalase pathway including Glo1 and Glo2 in liver and hypothalamus, and $d L D H$ (D-lactate dehydrogenase) in hypothalamus. Based on their biological function and location near the peak of the QTL, further analyses of Glo1 and Glo2 were conducted. Using qRTPCR, Glo1 was upregulated by 1.6- (chow) and 3-fold (macronutrient selection) in B6.CAST-17 congenic mice compared with wild-type controls (fig. 3a). Western blot analyses of Glol in liver yielded a single $\sim 21-\mathrm{kDa}$ band in both B6.CAST-17 congenic and wild-type B6 mice corresponding to the expected molecular weight of $20.7 \mathrm{kDa}$ (fig. 3b). Consistent with the observed strain difference in Glo1 mRNA and protein expression, congenic mice displayed higher enzymatic activity compared with WT $(23.5 \pm 2.3$ vs. $16.1 \pm 1.9 \mu \mathrm{mol} / \mathrm{min} / \mathrm{mg}, \mathrm{p}<0.05)$ (fig. 4$)$. 


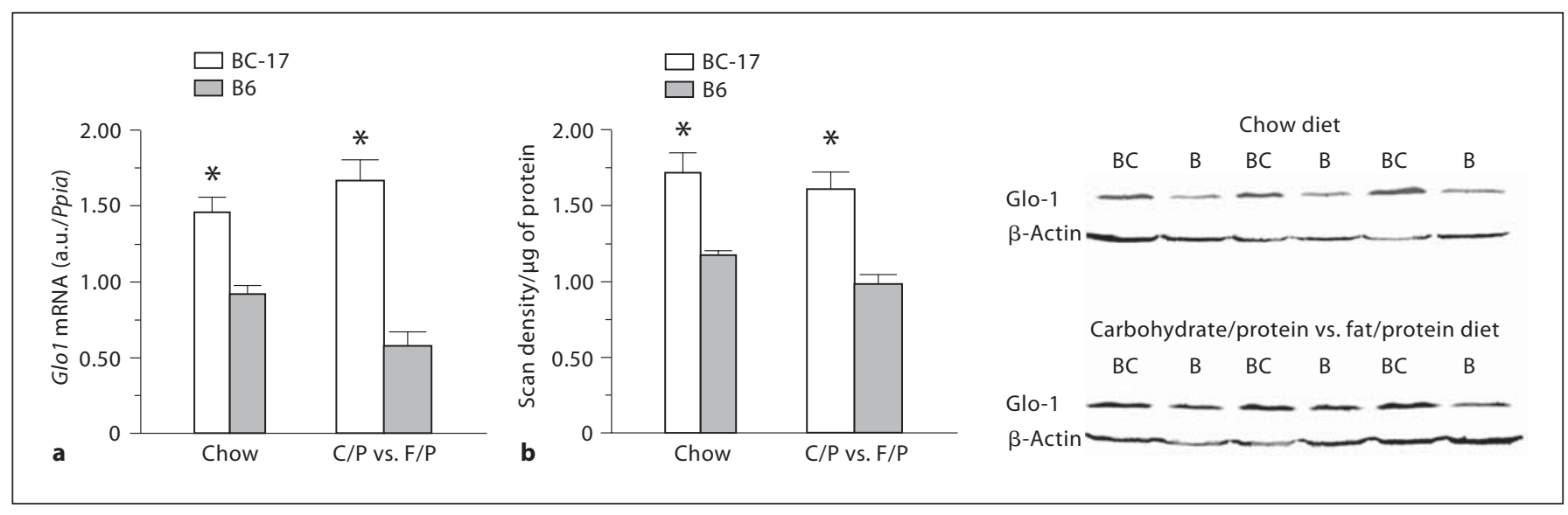

Fig. 3. Expression pattern of Glo1 in mouse liver. a qRT-PCR expression of Glo1 mRNA in wild-type B6 and homozygous B6.CAST-17 (BC-17) congenic mice. Data are expressed as mean \pm SE from 7-11 mice per strain, per diet, analyzed in duplicate. b Western blot analyses of liver yielded a single $\sim 20$-kDa band in wild-type B6 (B) and homozygous B6.CAST-17 (BC) corresponding to the known molecular weight of $21 \mathrm{kDa}$. Mouse $\beta$-actin antibody was applied as a loading control. ${ }^{*} \mathrm{p}<0.01$. Glo1, glyoxalase 1.

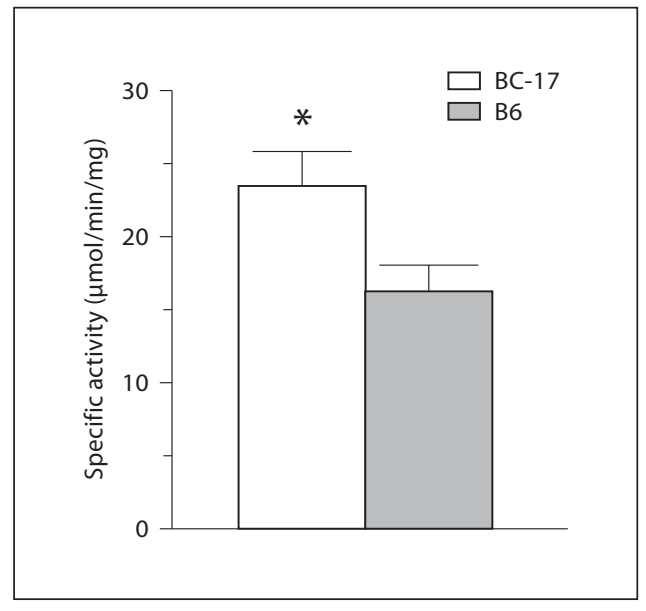

Fig. 4. Glyoxalase 1 enzyme activity in the blood of wildtype B6 $(\mathrm{n}=11)$ and homozygous B6.CAST-17 (BC-17) congenic $(\mathrm{n}=7)$ mice. Activity was measured as the rate of production of S-lactoylglutathione $\left(\varepsilon 3.37 \mathrm{~mm}^{-1} \mathrm{~cm}^{-1}\right)$ at $240 \mathrm{~nm}$ at 15 -second interval for $3 \mathrm{~min}$ and corrected for background by subtracting the $\mathrm{OD}_{240}$, measured before adding blood. Specific activity was expressed as $\mu \mathrm{mol}$ S-lactoylglutathione formed $/ \mathrm{min} / \mathrm{mg}$ protein. ${ }^{*} \mathrm{p}<0.05$.

To investigate whether increased Glo1 expression in the congenic strain was primary or a result of high carbohydrate feeding, we fed the animals a high- $(73 \%)$ or lowcarbohydrate (26\%) diet for 2 days and then examined Glo1 mRNA levels using qPCR. A strain difference of similar magnitude was observed both in hypothalamus (3-3.5-fold) $[F(1,20.7)=38.0, \mathrm{p}<0.0001]$ and in liver $(2.4-2.8$-fold $)[F(1,23.6)=110.43, \mathrm{p}<0.0001]$. Within strain, we found no differences in Glol expression as a function of low- or high-carbohydrate feeding for either hypothalamus $[F(1,20.7)=0.00, \mathrm{p}=0.98]$ or liver $[F(1$, 23.6) $=0.15, \mathrm{p}=0.71]$ (fig. 5).

\section{Expression of QTL Transcripts Unique to Chow}

Of ten genes that were differentially expressed in liver and unique to chow, none appeared to be promising candidates with respect to gene classification or known biological functions (table 4). Of the three differential genes in hypothalamus that were unique to chow, two were unknown and one encodes for a nuclear envelope membrane protein (Nurim) of speculative function (table 2).

\section{Expression of QTL Transcripts Unique to \\ Macronutrient Selection Diet}

In the hypothalamus, 57 regulated genes were found to be unique to macronutrient selection diet, including a regulator of G-protein signaling (Rgs11) [29] and several metabolic genes: Agpat1 (1-acylglycerol-3-phosphate Oacyltransferase 1), Lpin2 (lipin 2), M6pbp4 (mannose-6phosphate receptor binding protein 1), and Man2a1 (mannosidase 2, alpha 1) (table 2). Recombinant lipin-2 has been shown to have phosphatidate phosphatase type-1 (PAP1) activity, which has a key role in glycerolipid synthesis [30]. Also unique to the 2-choice diet was Probe ID \#853033, an EST that was downregulated by $>13$-fold in 
Fig. 5. qRT-PCR expression of Glo1 mRNA in wild-type $\mathrm{B} 6$ and homozygous $\mathrm{B} 6$. CAST-17 (BC-17) congenic mice fed a HC (high-carbohydrate; 73\%) or LC (low-carbohydrate; $26 \%$ ) diet for 2 days. Data are expressed as mean \pm SE from 9 mice per strain, per diet, analyzed in duplicate.

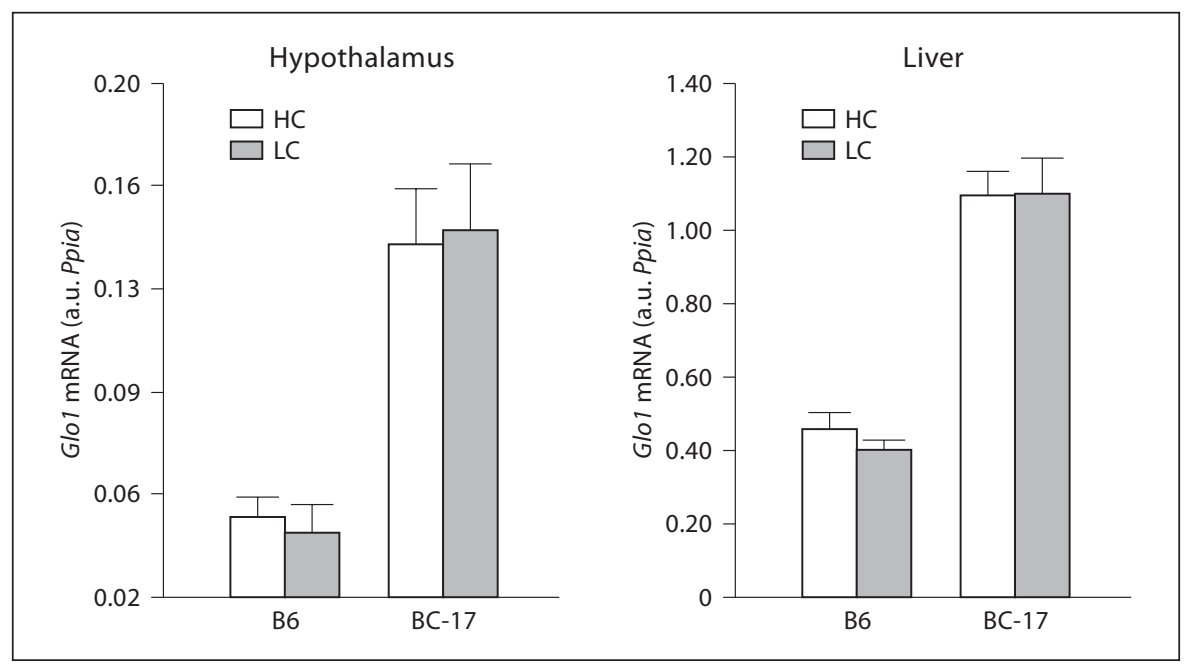

Table 4. QTL region genes that were differentially expressed only in chow or in macronutrient selection diet in liver

\begin{tabular}{|c|c|c|c|}
\hline Probe ID & Gene name & UniGene ID & Fold change \\
\hline \multicolumn{4}{|l|}{ Chow } \\
\hline 431279 & histocompatibility 2 , class II antigen $\mathrm{A}$, alpha & Mm.235338 & -3.54 \\
\hline 848612 & phosphatidylinositol glycan, class W & & -2.00 \\
\hline 542645 & olfactory receptor 121 & Mm.223020 & -1.82 \\
\hline 898280 & DNA segment, Chr 17, ERATO Doi 441, expressed & Mm.371601 & -1.53 \\
\hline 841838 & zinc finger protein 40 & Mm.21025 & 1.52 \\
\hline 506800 & triggering receptor expressed on myeloid cells-like 4 & Mm.131234 & 1.61 \\
\hline 820967 & BING4 protein & Mm.2437 & 1.65 \\
\hline 508816 & unassigned & Mm.26553 & 1.98 \\
\hline 697656 & protein containing single MORN motif in testis & Mm.45208 & 2.03 \\
\hline 586949 & histocompatibility $2, \mathrm{O}$ region alpha locus & Mm.116 & 2.29 \\
\hline \multicolumn{4}{|c|}{ Macronutrient selection diet } \\
\hline 650378 & histocompatibility 2 , blastocyst & Mm.34289 & 5.06 \\
\hline 618358 & tripartite motif protein 39 & Mm.40624 & 3.60 \\
\hline 729309 & coiled-coil alpha-helical rod protein 1 & Mm.49544 & 2.38 \\
\hline 897853 & PHD finger protein 20 -related & & 2.33 \\
\hline 706765 & expressed sequence AW494914 & Mm.12412 & 1.88 \\
\hline 436920 & chloride intracellular channel 5 & Mm.37666 & 1.71 \\
\hline 326220 & mitochondrial ribosomal protein $\mathrm{S} 10$ & Mm.358901 & 1.69 \\
\hline 502359 & cDNA sequence $\mathrm{BC} 027072$ & Mm.134151 & 1.65 \\
\hline 740898 & cDNA sequence $\mathrm{BC} 051226$ & Mm.250393 & 1.64 \\
\hline 452215 & DNA segment, Chr 17, Wayne State University 155 , expressed & Mm.303441 & 1.62 \\
\hline 324675 & olfactory receptor 94 & Mm.377382 & 1.56 \\
\hline 580896 & ribosomal protein $\mathrm{L} 10 \mathrm{a}$ & Mm.347060 & -1.58 \\
\hline 599654 & gametogenetin binding protein 1 & Mm.370478 & -1.59 \\
\hline 682803 & vomeronasal 2, receptor, 6 & Mm.246564 & -1.61 \\
\hline 919265 & RIKEN cDNA 1600012H06 gene & Mm.28544 & -1.61 \\
\hline 906020 & phosphodiesterase 9A & Mm.10812 & -1.66 \\
\hline 795040 & CD2 associated protein & Mm.218637 & -1.69 \\
\hline 697457 & chromosome transmission fidelity factor 18 homolog & Mm.102540 & -2.20 \\
\hline 780705 & unassigned & & -2.89 \\
\hline 854091 & triggering receptor expressed on myeloid cells-like 1 & Mm.90177 & -3.07 \\
\hline
\end{tabular}


Fig. 6. Pathways involved in glycolysis and the activation of the glyoxalase system. Methylglyoxal from glyceraldehydes-3phosphate and dihydroxyacetone-phosphate (DHA-P) is converted to D-lactate by glyoxalase enzymes. D-Lactate dehydrogenase converts D-lactate to pyruvate. Genes in shaded boxes were upregulated in the liver of B6.CAST-17 congenic mice.
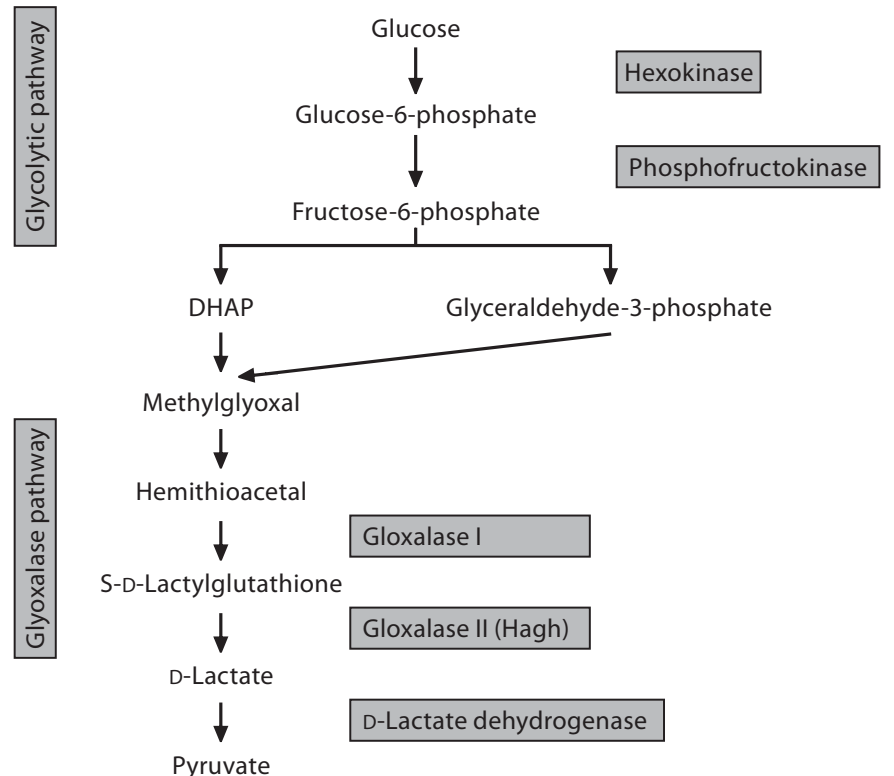

Pyruvate
Table 5. Differentially expressed glycolysis genes in liver, in the macronutrient selection diet protocol

\begin{tabular}{llrl}
\hline Probe ID & Gene name & $\begin{array}{l}\text { Fold } \\
\text { change }\end{array}$ & UniGene \\
\hline 434034 & hexokinase & 1.48 & $\mathrm{Mm} .196605$ \\
434336 & phosphofructokinase & 1.42 & $\mathrm{Mm} .132391$ \\
429576 & aldolase 3C isoform & 1.48 & $\mathrm{Mm} .7729$ \\
486053 & triose phosphate isomerase & -1.14 & $\mathrm{Mm} .391520$ \\
903599 & glyceraldehyde-3-phosphate & 1.39 & $\mathrm{Mm} .317779$ \\
& dehydrogenase & 2.19 & $\mathrm{Mm} .8359$ \\
336724 & pyruvate kinase & 1.66 & $\mathrm{Mm} .261984$ \\
915442 & glyoxalase 1 & 1.31 & $\mathrm{Mm} .43784$ \\
613660 & glyoxalase 2 (Hagh) & 1.73 & $\mathrm{Mm} .27210$ \\
902722 & glucose-6-phosphate & & \\
& dehydrogenase X-linked & & \\
\hline
\end{tabular}

the hypothalamus of congenic mice (table 2). In liver, 20 regulated genes were unique to the 2 -choice diet including several ESTs and uncharacterized genes, but interestingly, none of these genes are involved in metabolism (table 4).

\section{Gene Expression Differences Outside the QTL}

By comparing gene expression in the hypothalamus of congenic and WT mice while on chow diet, we identified
936 genes that were upregulated and 996 genes that were downregulated. In the liver, 775 genes were overexpressed and 812 genes were underexpressed in congenic mice. On the macronutrient selection diet, 618 genes were overexpressed in the hypothalamus of congenic mice and 647 downregulated. In liver, 875 genes were overexpressed in congenic mice and 1,019 downregulated.

\section{Glycolysis Pathway}

Our finding that the glyoxalase system was activated in B6.CAST-17 congenic mice led to an examination of genes upstream of this pathway, which revealed that several glycolytic genes outside the QTL were upregulated in this strain, in the macronutrient diet protocol, but not with chow diet (table 5). Specifically, all genes that code for enzymes involved in the conversion of glucose to 3carbon groups (glyceraldehyde-3-phosphate - G3P and di-hydroxy acetone phosphate - DHAP) were upregulated in the congenic strain (fig. 6).

\section{Wht Signaling Pathway}

Several genes representing Wnt signaling and located outside the QTL, showed altered expression in liver, i.e. Hoxc4, Ccnd3, Fzd7, Wnt3a, Wnt10b, and Csnk1. The Wnt transcripts Wnt10b, Fzd8, Wnt3, and Wnt6 were downregulated in congenic mice with macronutrient selection 
Table 6. Validation by qRT-PCR of selected gene candidates identified by microarray analysis

\begin{tabular}{|c|c|c|c|c|c|c|}
\hline \multirow[t]{3}{*}{ Gene Name } & \multicolumn{3}{|l|}{ Chow } & \multicolumn{3}{|c|}{$\begin{array}{l}\text { Macronutrient selection } \\
\text { (fat vs. carbohydrate) }\end{array}$} \\
\hline & \multirow{2}{*}{$\begin{array}{l}\text { array fold } \\
\text { change }\end{array}$} & \multicolumn{2}{|c|}{ real-time qPCR } & \multirow{2}{*}{$\begin{array}{l}\text { array fold } \\
\text { change }\end{array}$} & \multicolumn{2}{|c|}{ real-time qPCR } \\
\hline & & fold change & $\mathrm{p}$ value & & fold change & $\mathrm{p}$ value \\
\hline \multicolumn{7}{|l|}{ Hypothalamus } \\
\hline 1-Acylglycerol-3-phosphate O-acyltransferase 1 & & & & -2.1 & -1.7 & 0.041 \\
\hline Probe ID: $731526^{*}$ & & & & -2.45 & -2.19 & $<0.001$ \\
\hline Probe ID: $853033^{*}$ & & & & -13.4 & -1.7 & $<0.001$ \\
\hline Probe ID: $905863^{*}$ & & & & 2.71 & 1.45 & $<0.001$ \\
\hline Glyoxalase 1 & 2.71 & 2.68 & $<0.001$ & 1.59 & 3.05 & $<0.001$ \\
\hline Regulator of G-protein signaling 11 & & & & -1.65 & -0.04 & 0.61 \\
\hline \multicolumn{7}{|l|}{ Liver } \\
\hline Apolipoprotein M & -3.09 & -2.21 & $<0.001$ & -2.92 & -2.1 & $<0.001$ \\
\hline Cytochrome P450 family 4 subfamily f polypeptide 14 & -3.42 & -2.9 & $<0.001$ & -2.95 & -2.2 & $<0.001$ \\
\hline 2-4-dienoyl-Coenzyme A reductase 2, peroxisomal & -6.29 & -2.6 & 0.003 & -4.93 & -1.54 & 0.002 \\
\hline Glyoxalase 1 & 1.32 & 1.59 & $<0.001$ & 1.66 & 2.72 & $<0.001$ \\
\hline Glyoxalase 2 & 1.2 & 1.21 & 0.017 & 1.31 & 1.42 & 0.088 \\
\hline Trefoil factor 3 & 79.74 & 31.1 & $<0.001$ & 9.61 & 23.2 & $<0.001$ \\
\hline Transmembrane protein 8 & -1.75 & -23.2 & $<0.001$ & 1.75 & -41.1 & $<0.001$ \\
\hline Insulin-like growth factor-acid labile subunit & 1.42 & 1.06 & 0.82 & 1.48 & 1.1 & 0.65 \\
\hline Molybdenum cofactor synthesis 1 & 1.20 & 1.13 & 0.67 & 2.32 & 1.06 & 0.99 \\
\hline
\end{tabular}

Independent validation, using real-time RT-PCR, of selected gene candidates identified by microarray analysis. Fold change refers to the ratio of expression values of B6.CAST-17 congenic mice relative to wild-type B6. Statistical significance was calculated based on normalized threshold $\left(\mathrm{C}_{\mathrm{T}}\right)$ values.

* The curated gene information is not currently available.

diet but not with chow. Wnt10b was shown to decrease oxygen consumption in FABP4-Wnt10b mice although an effect on food intake has not been demonstrated [30]. The Wnt pathway has been linked to glycogen metabolism [32].

\section{PDGF (Platelet-Derived Growth Factor) Signaling}

Expression differences were noted in only four PDGF signaling genes in chow-fed mice (Vav2, Arhgap1, Srf, and Nck), but after $24 \mathrm{~h}$ of macronutrient diet selection, sixteen were differentially regulated between strains in both liver and hypothalamus, i.e. Stat1, Pkn3, Srgap2, Vav2, Mapk1, Mapk15, Mapk7, Sos1, Rps6ka2, Myc, Stard13, Jun, Rasa2, Stat5b, Arghap1, and Rab11b. Most of these changes were due to over-expression in congenics. PDGF signaling is involved in glucose transport and insulin stimulation [33], thus these patterns of transcriptional activity suggest regulatory systems invoked to support the congenic strain's high calorie intake in the form of carbohydrate.

Transcriptional Analyses of Nutrient Intake QTL

\section{Induction of Inflammatory Genes}

A number of genes involved in inflammation were differentially regulated in congenic mice, which is not surprising considering that the MHC is located within the QTL interval (tables 1, 3). The most markedly upregulated gene in the congenic strain was trefoil factor 3 (Tff3) located within the QTL region, which showed a high fold induction in liver that was validated by qPCR ( $>9$-fold). Also in liver, histocompatibility 2 and CD2 associated protein were altered. In the hypothalamus, the activated inflammatory genes included histocompatibility 2-T region locus 24, CD2 associated protein, $\mathrm{H} 2-\mathrm{K}$ region expressed gene 2, histocompatibility 2, and t-complexassociated genes, tumor necrosis factor (ligand) superfamily, member 9 and tumor necrosis factor receptor superfamily, member 21 .

\section{Validation of the Microarray Data by Real-Time qRT-PCR}

Because the genetic variation underlying nutrient intake traits resides within the QTL, a literature search was

J Nutrigenet Nutrigenomics 2008;1:155-171 
performed for all differentially regulated transcripts in this region. Candidates were chosen for independent validation based on known function, e.g. in metabolism, signaling, or based on a large fold difference in the microarray. Three uncharacterized ESTs were selected which showed enriched expression in brain. Most of the genes subjected to qRT-PCR analysis were confirmed, with the exception of Rgs11 (regulator of G-protein signaling), Igfals (insulin-like growth factor-acid labile subunit) and Mocs (molybdenum cofactor synthesis 1) (table 6), while the results obtained for Glo2 were marginal ( $\mathrm{p}<0.09)$. The novel transmembrane protein 8 (Tmem 8 ) drew interest because it was regulated in opposite direction with respect to diet, but when measured by qRT-PCR, was decreased in both diet protocols by 20 - to 40 -fold in congenic mice.

\section{Discussion}

Increased carbohydrate and total calorie intake share overlapping linkage on mouse chromosome 17 [17]. We have combined the use of microarrays with an intervalspecific congenic strain in an unbiased approach to identify candidate genes for these complex traits. Previously, we reported confirmation of these linked regions in a congenic strain, and an evaluation of positional candidates [18]. QTL can be manifest by a polymorphism(s) that affects either the expression level of a gene or the amount or function of a protein/gene [34]. Gene expression profiling has been used successfully to find genes and identify molecular mechanisms that underlie QTLs [35]. Based on our analyses, a number of genes and pathways showed altered expression which may be involved in the preferential consumption of fat or carbohydrate.

Genomic responses unique to macronutrient diet selection, assayed in hypothalamus, include the more than 2-fold decrease in Agpat1 and several ESTs. Agpat1 was decreased in the hypothalamus after $24 \mathrm{~h}$ of diet self-selection but was unaltered on chow. Further studies will allow us to determine the effects of diet on gene expression of these candidates and thereby achieve a more complete understanding of these complex traits [36]. Acyltransferases are involved in de novo biosynthesis of glycerolipids, such as phospholipids and triacylglycerol. AGPAT exists in at least five isoforms in humans, and all catalyze the same biochemical reaction [37]. Agpat1 (1acyl-sn-glycerol3-phosphate acyltransferase;EC 2.3.1.51), also known as lysophosphatidic acid acyltransferase (LPAAT), catalyses the conversion of lysophosphatidic acid to phosphatidic acid (PA). For example, PA can be hydrolyzed to yield diacylglycerol, a second messenger that can activate the brain-specific gamma isotype of protein kinase C (PKC gamma) [38].

Irrespective of diet, a number of genes involved in lipid metabolism were decreased in carbohydrate-preferring, congenic mice, while several genes associated with carbohydrate metabolism were increased. With respect to carbohydrate metabolism, our analyses uncovered the clear transcriptional regulation of glyoxalase in the hypothalamus and liver of B6.CAST-17 congenic mice, in response to both the high-carbohydrate chow and macronutrient selection diets. In a separate experiment, we determined that this strain difference in Glo1 expression was present, in similar magnitude, with low- as well as high-carbohydrate feeding. These results provide evidence for intrinsic strain variation in Glol expression which may constitute a basis for the QTL effect. We next sequenced the coding region of Glo1 and observed no amino acid changes in the open reading frame [18]. The position of the QTL peak over Glo1 suggests that a regulatory variant interacting with Glo1 may be located near, or within the gene.

The two primary genes in this pathway, glyoxalase 1 (Glo1) and glyoxalase 2 (Glo2) are located within the confidence interval of the Chr 17 QTL which is responsible for increased carbohydrate consumption. Glyoxalase 1 catalyzes the conversion of methylglyoxal (MG) and glutathione to S-lactoylglutathione which is then converted to D-lactate by glyoxalase 2 . MG is a metabolic by-product of glycolysis that is also produced during food processing and can be toxic if excess levels are accumulated [39]. If not catalyzed by the glyoxalase system, MG participates in the glycation of proteins and nucleotides, resulting in the formation of advanced glycation end products (AGEs) that can lead to mutagenesis, apoptosis, protein degradation and induction of pro-inflammatory cytokines [40]. Given that the B6.CAST-17 congenic strain consumes more carbohydrate, we would expect that it also produces a higher flux of methylglyoxal. If MG flux is high, increased Glo1 expression may be required to protect the proteome and genome. In support of this proposition, we found a significant upregulation of glyoxalase $1 \mathrm{mRNA}$ and protein expression in B6. CAST-17 congenic mice. Enzymatic activity paralleled the observed strain differences in expression. We propose that increased glyoxalase activity protects this congenic strain against dietary oxidants occurring as a result of high carbohydrate consumption.

Further evidence to suggest possible higher MG production in the B6.CAST-17 congenic line was found in 
that carbohydrate-preferring congenic mice showed enhanced expression of glycolytic genes upstream of dihydroxy acetone phosphate (DHAP) formation, i.e. hexakinase and phosphofructokinase (fig. 6; table 5). Once fructose 1,6-diphosphate is cleaved into DHAP and glyceraldehyde- 3 phosphate, these molecules act as precursors for the nonenzymatic formation of methylglyoxal. The end product of glyoxalase action is D-lactate which is converted to pyruvate by D-lactate dehydrogenase (ldhd), a mitochondrial enzyme [41]. We observed that ldhd expression was $>1.5$-fold higher in the hypothalamus of congenic mice, providing evidence for the conversion of excess D-lactate to pyruvate (fig. 6).

The available data from our study and others point to a possible link between Glo1 expression and ingestive behavior. We have shown previously that the $129 / \mathrm{J}$ and BALBcByJ prefer dietary carbohydrate over fat, whereas C57BL/6J and DBA/2J preferentially consume fat in a macronutrient diet selection paradigm [16]. A recent study found that Glo1 was upregulated in the brain of the carbohydrate-preferring 129/J and BALBcByJ strains, and decreased in the fat-preferring C57BL/6J and DBA/2J [42]. Together, these results suggest an association between increased Glo1 expression and carbohydrate preference in mouse inbred strains. An association of glyoxalase 1 with feeding behavior has not been identified but may yield new insight on the functional effects of this metabolic pathway. Glo1 has also been linked to anxiety [42], although this connection has been questioned [43], and the regulation of theta oscillations during sleep [44]. The physiological function of Glo1 in the brain is mostly unknown. It has been proposed that neuronal damage by excess methylglyoxal could contribute to increased anxiety [43]. Further studies are needed to examine mechanisms by which Glo1 expression and activity could alter neuronal function and, ultimately, behavior.

Other QTL genes with key metabolic functions in lipid metabolism were decreased in the liver of carbohydrate-preferring mice, despite the equivalent fat intake between strains. The encoded protein for Decr 2 increases the conversion of delta2-trans, delta4-trans-decadienoyl coenzyme A to delta3-enoyl coenzyme A and is involved in the peroxisomal oxidation of very long chain, polyunsaturated fatty acids [45]. ApoM encodes an apolipoprotein found mainly in high-density lipoproteins (HDL), that appears to play a role in the prevention of atherosclerosis possibly through its anti-inflammatory effects [46]. The ACAT2 enzyme is responsible for synthesis of plasma lipoprotein cholesteryl esters. A role for any of these candidates in pathways regulating food intake has not been established. Alternatively, these results may have relevance to other QTL on mouse Chr 17 for atherosclerosis (Ath26) [47] or for obesity (Obq4) [48].

A large number of genes associated with inflammatory processes were induced in congenic mice which showed no apparent clinical signs of inflammation. However, this result could reflect a genomic response to nutrient intake. For example, the increased expression of inflammatory genes in high carbohydrate-consuming congenic mice is consistent with reports of a pro-inflammatory effect of glucose intake in human subjects [49]. Thus in our model, high carbohydrate intake may alter the expression of mRNAs related to inflammation.

The highest fold difference in gene expression and confirmed by qPCR, was for the hepatic expression of trefoil factor 3 (Tff3), located in the peak of the QTL (table 6). TFF3 is an extracellular, secretory polypeptide that resists proteolytic degradation. TFF3 is expressed in several mammalian tissues but is found predominantly in the gastrointestinal tract where it protects and contributes to healing of the mucosal barrier [50]. In liver, TFF3 contributes to epithelial cell migration and wound healing [51]. Interestingly, higher Tff3 expression has been reported in the liver of B6 mice when compared with Tally Ho (TH) mice, a model of diabesity [52]. Consistent with this observation, Tff3 maps to Obq4, an obesity QTL on mouse chromosome 17 [48]. A possible role of Tff3 in dietary obesity remains to be established, along with its expression profile in relevant tissues such as muscle and adipose.

Because the mechanisms responsible for macronutrient diet selection are unknown, the key tissue(s) underlying the phenotypes can only be inferred at this stage of analysis. These results were obtained from an examination of gene expression in the hypothalamus and liver, yet genetic and genomic data from our laboratory [18] indicate that at least one molecular component of the QTL may reside in other tissues. Specifically, the Chr 17 QTL approximate the location of Glplr (glucagon-like peptide 1 receptor), a compelling candidate gene for this QTL with respect to its expression in antral stomach [18]. Elucidating the molecular basis of complex traits such as those involving ingestive behavior will likely require the characterization of gene expression in multiple tissues, the central nervous system notwithstanding.

In conclusion, our results reveal patterns of altered gene expression, resulting from a CAST segment of proximal Chr 17, for genes involved in metabolism, inflammation, and oxidative stress, any of which could be linked to phenotypic preferences for carbohydrate or fat. Genes in the Wnt signaling and PDGF signaling pathways were 
also upregulated and thus may be implicated in carbohydrate metabolism. More specifically, these data support the hypothesis that mice genetically predisposed to eat more carbohydrate and total energy per body weight are protected against the stress of dietary oxidants through induction of the glyoxalase system. Sequence and expression analyses, as well as functional studies in our mice will establish the viability of candidates such as Agpat1 and Glo1, e.g. by overexpressing and/or silencing these genes by means of lentiviral transduction.

\section{Acknowledgments}

We thank Dr. Barbara York for assistance with the tissue dissections and analyses of phenotypic data. This research was supported by a grant from the National Institute of Diabetes and Digestive and Kidney Diseases to B.K.S.R. (DK-53113).

\section{References}

1 Birch LL: Children's preferences for high-fat foods. Nutr Rev 1992;50:249-255.

2 Blundell JE, Cooling J: Routes to obesity: phenotypes, food choices and activity. Br J Nutr 2000;83(suppl 1):S33-S38.

3 de Castro JM: What are the major correlates of macronutrient selection in Western populations? Proc Nutr Soc 1999;58:755-763.

4 Dreon DM, Frey-Hewitt B, Ellsworth N, Williams PT, Terry RB, Wood PD: Dietary fat:carbohydrate ratio and obesity in middle-aged men. Am J Clin Nutr 1988;47:9951000.

5 Falciglia GA, Norton PA: Evidence for a genetic influence on preference for some foods. J Am Diet Assoc 1994;94:154-158.

6 Geiselman PJ, Anderson AM, Dowdy ML, West DB, Redmann SM, Smith SR: Reliability and validity of a macronutrient self-selection paradigm and a food preference questionnaire. Physiol Behav 1998;63:919-928.

7 Macdiarmid JI, Cade JE, Blundell JE: High and low fat consumers, their macronutrient intake and body mass index: further analysis of the national diet and nutrition survey of British adults. Eur J Clin Nutr 1996;50:505512.

8 Pilgrim J, and Patton RA: Patterns of self-selection of purified dietary components by the rat. J Comp Physiol Psychol 1947;40:343348.

9 Scott EM: Self selection of diet. J Nutr 1946; 31:397-406.

10 York DA, Lin L, Smith BK, Chen J: Enterostatin as a regulator of fat intake; in Berthoud HR, Seeley RJ (eds): Neural and Metabolic Control of Macronutrient Intake. Boca Raton, CRC Press, 2000, pp 361-387.

11 Okada S, York DA, Bray GA, Mei J, ErlansonAlbertsson C: Differential inhibition of fat intake in two strains of rat by the peptide enterostatin. Am J Physiol 1992;262:R1111R1116.

12 Overmann SR: Dietary self-selection by animals. Psychol Bull 1976;83:218-235.
13 Smith BK, West DB, York DA: Carbohydrate vs. fat intake: differing patterns of macronutrient selection in two inbred mouse strains. Am J Physiol 1997;272:R357-R362.

14 Smith, BK, Berthoud H-R, York DA, Bray GA: Differential effects of baseline macronutrient preferences on macronutrient selection after galanin, NPY, and an overnight fast. Peptides 1997;18:207-211.

15 Shor-Posner G, Ian C, Brennan G, Cohn T, Moy H, Ning A, Leibowitz SF: Self-selecting albino rats exhibit differential preferences for pure macronutrient diets: characterization of three subpopulations. Physiol Behav 1991;50:1187-1195.

16 Smith BK, Andrews PK, West DB: Macronutrient diet selection in thirteen mouse strains. Am J Physiol 2000;278:R797-R805.

17 Smith Richards BK, Belton BN, Poole AC, Mancuso JJ, Churchill GA, Li R, Volaufova J, Zuberi A, York B: QTL analysis of self-selected macronutrient diet intake: fat, carbohydrate, and total kilocalories. Physiol Genomics 2002;11:205-217

18 Kumar KG, Poole AC, York B, Volaufova J, Zuberi A, Smith Richards BK: Quantitative trait loci for carbohydrate and total energy intake on mouse Chromosome 17: Congenic strain confirmation and candidate gene analyses (Glo1, Glp1r). Am J Physiol 2007; 292:R207-R216.

19 Wakeland E, Morel L, Achey K, Yui M, Longmate J: Speed congenics: a classic technique in the fast lane (relatively speaking). Immunol Today 1997; 18:472-477.

20 Berthoud HR: An overview of neural pathways and networks involved in the control of food intake and selection; in Berthoud HR, Seeley RJ (eds): Neural and Metabolic Control of Macronutrient Intake. Boca Raton, CRC Press, 2000, pp 361-387.

21 Cupples WA: Physiological regulation of food intake. Am J Physiol 2005;288:R1438R1443.

22 Friedman MI, Horn CC, Ji H: Peripheral signals in the control of feeding behavior. Chem Senses 2005;30(suppl 1):i182-i183.
23 Horn CC, Addis A, Friedman MI: Neural substrate for an integrated metabolic control of feeding behavior. Am J Physiol 1999;276: R113-R119.

24 Levin BE: Metabolic sensing neurons and the control of energy homeostasis. Physiol Behav 2006;89:486-489.

25 Smith Richards BK, Belton BN, York B, Volaufova J: Mice bearing Acads mutation display altered postingestive but not 5 -s orosensory response to dietary fat. Am J Physiol 2004;286:R311-R319.

26 Woods SC, Lutz TA, Geary N, Langhans W: Pancreatic signals controlling food intake; insulin, glucagon and amylin. Phil Trans R Soc Lond [B] 2006;361:1219-1235.

27 Bolstad BM, Irizarry RA, Astrand M, Speed TP: A comparison of normalization methods for high density oligonucleotide array data based on bias and variance. Bioinformatics 2003;19:185-193.

28 Han LP, Davison LM, Vander Jagt DL: Purification and kinetic study of glyoxalase-I from rat liver, erythrocytes, brain and kidney. Biochim Biophys Acta 1976;445:486499

29 Dong MQ, Chase D, Patikoglou GA, Koelle MR: Multiple RGS proteins alter neural G protein signaling to allow $C$. elegans to rapidly change behavior when fed. Genes Dev 2000;14:2003-2014.

30 Donkor J, Sariahmetoglu M, Dewald J, Brindley DN, Reue K: Three mammalian lipins act as phosphatidate phosphatases with distinct tissue expression patterns. J Biol Chem 2007;282:3450-3457.

31 Longo KA, Wright WS, Kang S, Gerin I, Chiang SH, Lucas PC, Opp MR, MacDougald OA: Wnt10b inhibits development of white and brown adipose tissue. J Biol Chem 2004; 279:35503-35509.

32 Yamazaki H, Yanagawa S: Axin and the Axin/Arrow-binding protein DCAP mediate glucose-glycogen metabolism. Biochem Biophys Res Commun 2003;304:229-235. 
33 Whiteman EL, Chen JJ, Birnbaum MJ: Platelet-derived growth factor (PDGF) stimulates glucose transport in 3T3-L1 adipocytes overexpressing PDGF receptor by a pathway independent of insulin receptor substrates. Endocrinology 2003;144:3811-3820.

34 Flint J, Valdar W, Shifman S, Mott R: Strategies for mapping and cloning quantitative trait genes in rodents. Nat Rev Genet 2005;6: 271-286.

35 Aitman TJ, Glazier AM, Wallace CA, Cooper LD, Norsworthy PJ, Wahid FN, Al-Majali KM, Trembling PM, Mann CJ, Shoulders CC, Graf D, St Lezin E, Kurtz TW, Kren V, Pravenec M, Ibrahimi A, Abumrad NA, Stanton LW, Scott J: Identification of Cd36 (Fat) as an insulin-resistance gene causing defective fatty acid and glucose metabolism in hypertensive rats. Nat Genet 1999;21:7683.

-36 Kaput J, Rodriquez RL: Nutritional genomics: the next frontier in the postgenomic era. Physiol Genomics 2004;16:166-177.

- 37 Lu B, Jiang YJ, Man MQ, Brown B, Elias PM, Feingold KR: Expression and regulation of 1-acyl-sn-glycerol-3-phosphate acyltransferases in the epidermis. J Lipid Res 2005;46: 2448-2457.

38 Saito N, Shirai Y: Protein kinase C gamma (PKC gamma): function of neuron specific isotype. J Biochem (Tokyo) 2002;132:683687.
39 Ankrah NA, Appiah-Opong R: Toxicity of low levels of methylglyoxal: depletion of blood glutathione and adverse effect on glucose tolerance in mice. Toxicol Lett 1999; 109:61-67.

40 Thornalley PJ: Glutathione-dependent detoxification of $\alpha$-oxoaldehydes by the glyoxalase system: involvement in disease mechanisms and antiproliferative activity of glyoxalase I inhibitors. Chem Biol Interact 1998; 111-112:137-151.

41 Bari L, Atlante A, Guarangnella N, Principata G, Passarella S: D-Lactate transport and metabolism in rat liver mitochondria. Biochem J 2002;365:391-403.

42 Hovatta I, Tennant RS, Helton R, Marr RA, Singer O, Redwine JM, Ellison JA, Schadt EE, Verma IM, Lockhart DJ, Barlow C: Glyoxalase 1 and glutathione reductase 1 regulate anxiety in mice. Nature 2005;438:662-666.

43 Thornalley PJ: Unease on the role of glyoxalase 1 in high-anxiety-related behaviour. Trends Mol Med 2006;12:195-199.

44 Tafti M, Petit B, Chollet D, Neidhart E, de Bilbao F, Kiss JZ, Wood PA, Franken P: Deficiency in short-chain fatty acid beta-oxidation affects theta oscillations during sleep. Nat Genet 2003;34:320-325.

45 Geisbrecht BV, Liang X, Morrell JC, Schulz $\mathrm{H}$, Gould SJ: The mouse gene PDCR encodes a peroxisomal delta(2), delta(4)-dienoylCoA reductase. J Biol Chem 1999;274:2581425820 .
46 Huang XS, Zhao SP, Hu M, Luo YP: Apolipoprotein M likely extends its anti-atherogenesis via anti-inflammation. Med Hypotheses 2007;69:136-40. Epub 2007 Jan 10.

47 Smith JD, Bhasin JM, Baglione J, Settle M, Xu Y, Barnard J: Atherosclerosis susceptibility loci identified from a strain intercross of apolipoprotein E-deficient mice via a highdensity genome scan. Aterioscler Thromb Vasc Biol 2006;26:597-603.

48 Taylor BA, Phillips SJ: Obesity QTLs on mouse chromosomes 2 and 17. Genomics 1997;43:249-257.

49 Aljada A, Friedman J, Ghanim H, Mohanty P, Hofmeyer D, Chaudhuri A, Dandona P: Glucose ingestion induces an increase in intranuclear nuclear factor kappaB, a fall in cellular inhibitor kappaB, and an increase in tumor necrosis factor alpha messenger RNA by mononuclear cells in healthy human subjects. Metabolism 2006;55:1177-1185.

50 Taupin D, Podolsky DK: Trefoil factors: initiators of mucosal healing. Nat Rev Mol Cell Biol 2003;4:721-732.

51 Nozaki I, Lunz JG 3rd, Specht S, Park JI, Giraud AS, Murase N, Demetris AJ: Regulation and function of trefoil factor family 3 expression in the biliary tree. Am J Pathol 2004;165: 1907-1920.

52 Brown AC, Olver WI, Donnelly CJ, May ME, Naggert JK, Shaffer DJ, Roopenian DC: Searching QTL by gene expression: analysis of diabesity. BMC Genet 2005;6:12. 